\title{
New information of second-generation Landsat satellites for agricultural applications in the Netherlands
}

\author{
G. F. Epema \\ Department of Soil Science and Geology, Wageningen Agricultural University, \\ P.O. Box 37, NL 6700 AA Wageningen, Netherlands
}

Received 25 November 1986; accepted 28 May 1987

Key words: Landsat Thematic Mapper, remote sensing, spectral curves, principal components, crops

\begin{abstract}
The possibilities of the Landsat Thematic Mapper satellites were examined for agricultural purposes. By using statistical analysis and constructing reflectance spectra of ground cover types around Wageningen it was investigated whether the enhanced spectral information provided new possibilities in comparison with firstgeneration Landsat MSS. It was shown that especially TM band 5 is a useful addition to the normal information in the range of visible and near-infrared light, because some crops have a larger decrease in reflectance than others in this band. The low spatial resolution of the thermal band is a major limitation for many applications, although the information is additional to the bands at smaller wavelengths.
\end{abstract}

\section{Introduction}

For a large range of applications the Landsat satellites have shown to be valuable, since in 1972 the first Landsat was launched. There were, however, two major drawbacks for an extensive use of the data in the Netherlands:

- the spatial resolution was too low

- the spectral resolution was limited.

Landsat 4 and later satellites carry a Thematic Mapper, which has an increased spatial and spectral resolution (Table 1). The ground sample size of the Thematic Mapper is $30 \mathrm{~m} \times 30 \mathrm{~m}$ for all bands in the reflective part of the spectrum instead of about $80 \mathrm{~m} \times 80 \mathrm{~m}$ ground resolution for the first-generation Landsat MSS. Apart from an increase in number of bands, they are now more properly allocated for identification of crops, vegetation, soils and rocks (US Geological Survey, 1982).

Spatial resolution of Thematic Mapper imagery is such that most fields can be identified easily and contain a number of pure pixels. Also the radiometric sensitivity and accuracy of the Thematic Mapper is much better than for the first-generation 
Table 1. A comparison of some Landsat Thematic Mapper characteristics with the first-generation Landsat MSS.

\begin{tabular}{llll}
\hline $\begin{array}{l}\text { Channel } \\
\text { No }\end{array}$ & $\begin{array}{l}\text { MSS } \\
\text { (first generation) } \\
(\mu \mathrm{m})\end{array}$ & $\begin{array}{l}\text { Channel } \\
\text { No }\end{array}$ & $\begin{array}{l}\mathrm{TM} \\
(\mu \mathrm{m})\end{array}$ \\
4 & & & \\
5 & $0.5-0.6^{*}$ & 1 & $0.45-0.52^{*}$ \\
6 & $0.6-\left(0.7^{*}\right.$ & 2 & $0.52-0.60^{*}$ \\
7 & $0.7-0.8^{*}$ & 3 & $0.63-0.69^{*}$ \\
& $0.8-1.1^{*}$ & 4 & $0.76-0.90^{*}$ \\
& & 5 & $1.55-1.75^{*}$ \\
& & 7 & $2.08-2.35^{*}$ \\
& & 6 & $10.40-12.50^{* *}$
\end{tabular}

equivalent

pixel size: $56 \mathrm{~m} \times 79 \mathrm{~m}$

$30 \mathrm{~m} \times 30 \mathrm{~m}$

(bd 6: $120 \mathrm{~m} \times 120 \mathrm{~m}$ )

$*$ reflection; $* *$ thermic.

Landsat MSS. In this paper, however, attention is given mainly to the possibilities of spectral information of Thematic Mapper data. More specifically it is tested whether the new bands contain additional information for agricultural purposes. Since all information was gathered in a digital way, statistical tests could be applied easily to the data set.

\section{Methods}

There is a large variety of methods for displaying satellite information, such as single bands, ratios, combinations of colour bands, tasseled cap transforms, principal components, and classification. The treatments of the data range from simple to complicated and are based on statistics or on reflectance properties of the ground cover types. Although for many applications it is useful to make hard copies, in this study more attention is paid to the interpretation of the digital data themselves. This is a more objective way to study specific spectral information. Understanding of specific information may lead to improvement of imagery.

A Thematic Mapper tape of 22 August 1984 (Path 197 Row 24 Quarter 1) was available for this study. An area around Wageningen of about $15 \times 15 \mathrm{~km}$ was selected for this study, as it shows a large range of different geomorphological features, soils, vegetation and crops. For different data sets in this area correlation coefficients between all bands and principal components were calculated. Digital count numbers were converted to reflectance values using a method described by Menenti (1984). With this information representative spectral reflectance curves were constructed. These were derived from plots comparing all bands in pairs for a range of surface features.

The ground cover types were determined in the field or based on data of experimental farms. For location and a physiographic overview of the units an image has 
to be selected. A colour combination of band 3,4 and 5 proved to be useful. The scaling limits for the different colours were determined by the range of reflectance values of crops and bare soils, without considering water reflectance. Pure pixels were selected for the statistical analysis. It has to be noted that the quality of the 3 , 4,5 colour combination product for physiographic interpretation can be increased by applying a $25 \%$ Laplace filter over the image.

\section{Results and interpretation}

In Table 2 correlation matrices and principal components are presented for some representative data sets. These results are given with and without the thermal band 6. For land applications it seems justified to neglect open water. On almost every image it can be identified easily. The sets with water (not in tables) have some influence on the correlation and principal components.

In a physical sense it seems best to consider first the information of the bands in the reflective part of the spectrum (all but band 6). Some general conclusions can be drawn over the correlation coefficients:

- correlation coefficients between the first three bands are very high;

- the correlation coefficient between band 5 and 7 is relatively high;

- correlation coefficients of band 4 with other bands are low. Under the assumption that variation deals with information, the best bands can be chosen preliminary:

- band 4

- one band out of bands 1,2 and 3

- band 5 or 7

When we look to the principal components we may conclude the following.

- In a statistical sense almost all information is contained in the first three principal components.

- All bands in the PC1 have the same sign (positive). The PC1 represents information comparable with total reflectance or intensity. A difference with real intensity is that the weighing of the bands is not based on the incoming radiance per band width. Especially the low contribution of band 4 is remarkable.

- PC2 opposes band 4 (and 5) to the other bands.

- PC3 opposes bands 5 and 7 to the other bands.

These principal components agree well with other research on Thematic Mapper (Anuta et al., 1984). Moreover the results fit rather well with more physically based transformation of the data as the tasseled cap (Kauth \& Thomas, 1976; Crist \& Cicone, 1984). This method is very useful in temperate zones. In this method the three principal information axes in the data set are called brightness (intensity, especially of bare soils), greenness (band 4 opposed to the other bands; information on vegetation and vegetation cover) and what is called tentatively wetness by Crist $\&$ Cicone (1984) (bands 5 and 7 opposed to other bands; information on moisture content). Apart from relatively small differences in loadings, the largest discrepancy between the PCs and the tasseled cap remains the low loading of band 4 in PC1, indicating that some information is already present on vegetation in the first $\mathrm{PC}$. 
Table 2. Correlation coefficients and normalized principal components for the bands in the reflective part of the spectrum. and for bands 2 to 7 including thermal band 6 .

\begin{tabular}{llllllll}
\hline Band & 1 & 2 & 3 & 4 & 5 & 7 & 6 \\
1 & 1.00 & & & & & & \\
2 & 0.96 & 1.00 & & & & & \\
3 & 0.97 & 0.97 & 1.00 & & & & \\
4 & 0.05 & 0.19 & 0.04 & 1.00 & & & \\
5 & 0.76 & 0.82 & 0.79 & 0.48 & 1.00 & 1.00 & \\
7 & 0.90 & 0.92 & 0.94 & 0.17 & 0.91 & 0.23 & 1.00 \\
6 & 0.13 & 0.14 & 0.26 & -0.34 & 0.19 & &
\end{tabular}

\section{Eigenvector loadings per band}

\begin{tabular}{|c|c|c|c|c|c|c|c|}
\hline $\begin{array}{l}\text { Principal } \\
\text { compo- } \\
\text { nents }\end{array}$ & $\begin{array}{l}\text { Cumulative } \\
\text { percentage } \\
\text { of eigen- } \\
\text { values }\end{array}$ & 1 & 2 & 3 & 4 & 5 & 7 \\
\hline 1 & 77.26 & 0.443 & 0.454 & 0.450 & 0.113 & 0.422 & 0.453 \\
\hline 2 & 95.80 & -0.197 & -0.065 & -0.204 & 0.909 & 0.294 & -0.039 \\
\hline 3 & 98.92 & 0.397 & 0.395 & 0.136 & 0.325 & -0.616 & -0.427 \\
\hline 4 & 99.41 & 0.702 & -0.347 & -0.301 & -0.080 & 0.383 & -0.377 \\
\hline 5 & 99.78 & 0.330 & -0.493 & -0.081 & 0.193 & -0.456 & 0.629 \\
\hline 6 & 100 & 0.069 & 0.520 & -0.800 & -0.103 & -0.040 & 0.270 \\
\hline \multicolumn{8}{|c|}{ Eigenvector loadings per band } \\
\hline $\begin{array}{l}\text { Principal } \\
\text { compo- } \\
\text { nents }\end{array}$ & $\begin{array}{l}\text { Cumulative } \\
\text { percentage } \\
\text { of eigen- } \\
\text { values }\end{array}$ & 2 & 3 & 4 & 5 & 6 & 7 \\
\hline 1 & 63.73 & 0.496 & 0.498 & 0.044 & 0.483 & 0.139 & 0.502 \\
\hline 2 & 86.60 & 0.091 & -0.072 & 0.738 & 0.135 & -0.649 & -0.034 \\
\hline 3 & 97.18 & -0.114 & -0.166 & 0.613 & 0.151 & 0.738 & -0.126 \\
\hline 4 & 99.41 & -0.503 & -0.394 & -0.184 & 0.687 & -0.107 & 0.273 \\
\hline 5 & 99.85 & -0.309 & -0.025 & -0.188 & -0.499 & -0.027 & 0.864 \\
\hline 6 & 100 & 0.620 & -0.750 & -0.086 & -0.070 & 0.047 & 0.195 \\
\hline
\end{tabular}

With the first three principal components already more than $99 \%$ of the variation is explained. It has to be noted that in the remaining PCs important information may still exist. The PC1 and PC2 for MSS gives mostly a weighted summation and a difference between visible and near-infrared respectively. Hence they are alike the first two PCs for TM.

In Fig. 1 representative mean spectral curves are given for a range of surface features. Information on type of crops and vegetation was gathered in the field shortly after the TM overpass and based on available information of some experimental fields. The use of a large number of points in the plots of the different bands, give 


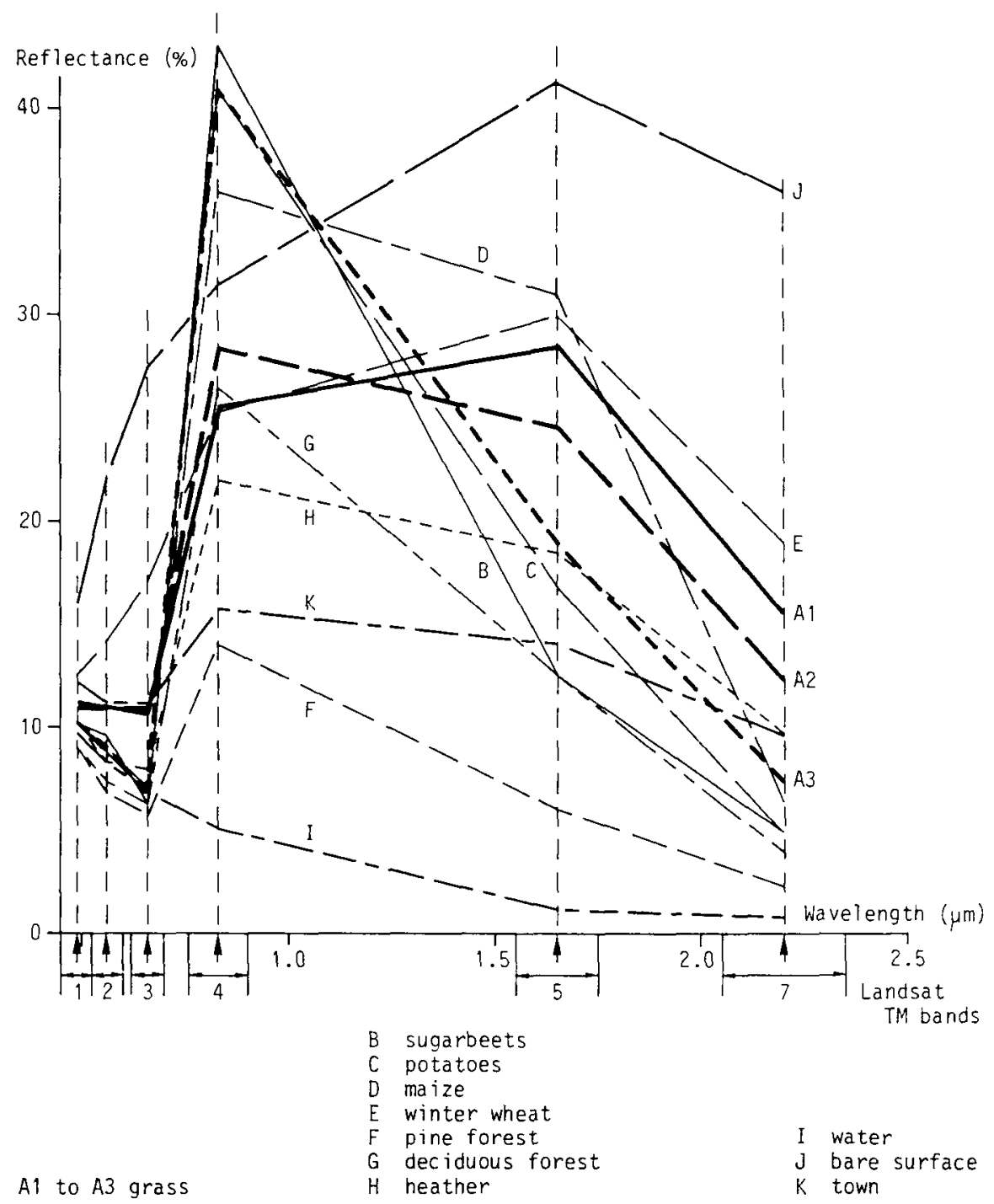

Fig. 1. Spectral curves of different units on Landsat Thematic Mapper of 22 August 1984 (the midpoints of the bands are connected).

also an indication of standard deviation and overlap of the clusters. For a careful selection of the used classes, the overlap is small.

From the curves it is clear that the reflectance for crop and vegetation in the visible bands 1,2, 3 is relatively low in comparison with the infrared (band 4). The low reflectance is due to the effect of pigmentation of the leaves in the visible part of the 
spectrum. Chlorophyll absorption produces very low reflectance values especially around $0.67 \mu \mathrm{m}$ and $0.45 \mu \mathrm{m}$. Therefore in the visible part the highest reflectance is around $0.55 \mu \mathrm{m}$, which produces a green colour for vegetation. The relatively high values of band 1 are caused by contribution of the atmosphere to reflectance. Correcting for the atmosphere will give a by 3 to $4 \%$ larger decrease in reflectance in band 1 than in band 2 . For most sites, fully covered by crops or natural vegetation, the reflectance in band 3 covers a rather narrow range. This band will be very useful for determining the cover or contribution of soil background. In the infrared plateau for vegetation the absorption is very low, especially for dense vegetation. Beyond this wavelength, absorption by the plant, especially due to water in the leaves, becomes important. Minima occur around 1.45 and $1.95 \mu \mathrm{m}$. Bands 5 and 7 are relative maxima respectively in the wavelength range between the water absorption bands and beyond the latter water band. Still also in bands 5 and 7 there is some influence of the water dips. Beets for instance having a high leaf water content show already in band 5 a larger decrease in reflectance than some other crops. This is in accordance with results of Verhoef \& Bunnik (1974). It has to be noted that the reflectance spectra of crops and vegetation depend on crop type (due to structure) and stage of growth. A partial cover gives a larger influence of soil in reflectance in all bands with the exception of band 4. The three selected grass plots in Fig. 1 show the influence of mowing and hence soil contribution to the signal. Grass of Al was the shortest. Also the health and type of grass may influence the reflectance, but this has not been examined in detail.

In general the reflectance of bare surfaces in comparison with vegetation is more evenly spread throughout the spectrum. At the time of Landsat overpass there were hardly any parts without vegetation. Therefore only the curve shape of a bare surface in a quarry could be given. It has to be noted that as a function of moisture content, roughness, organic matter and mineralogy important changes of reflectance may occur. Especially the amount of reflectance may vary, but for instance mineralogy and water content may also influence specific bands. Additionally it must be said that in this case a dry, rough surface is given.

The possibilities of the red and near-infrared band are well known. In comparison with the first generation Landsat MSS the range of values in the red band for vegetation is much smaller, indicating a better choice of the wavelength range in TM. The extra information in TM band 5 can also be read from the curves. Hence new possibilities are now present to identify crops. Moreover the relatively small decrease in reflectance from bands 5 to 7 for urban areas is also useful information. The blue band does not provide much new information. Moreover due to the small range of values and atmospheric influence interpretations are rather difficult.

In Table 2 also information is given on band 6, the thermal band. Information of this band has to be interpreted with caution.

The poorer ground resolution $(120 \mathrm{~m} \times 120 \mathrm{~m})$ is a limitation for application, and also influences to a certain extent the correlations with the other $30 \times 30 \mathrm{~m}^{2}$ bands. There may also be some constraints in using band 6 in principal components, since it contains essentially different information. The best way seems a separate use of band 6 for applications for which the pixel size is not a problem. An examination of 
the data suggests that there is certainly useful information in this band. If the ground resolution of band 6 will increase, there remains the problem that the time of Landsat overpass is not optimal. The main information present in band 6 will be discussed briefly. The correlation coefficients of band 6 with the other bands are positive, except with band 4 . This can be explained with reference to the feature space plots. Four groups could be discriminated in these plots with decreasing temperature:

- heather, urban settlements, bare surfaces

- most crops, grass

- forest, maize

- water

This indicates the well known fact that during daytime the temperature of bare surfaces is above that of vegetation and water. Moreover rough vegetation has a lower temperature than other types of vegetation. Some cover types show a large range of temperatures, while for other units a rather limited range existed. At one hand it gives the possibility for a further specification of the unit. At the other hand variation within the units, after eliminating the difference in cover, may give information on water stress. For both applications, use of TM band 6 is limited by the spatial resolution.

\section{Conclusions and discussion}

Although in this study only TM data of a single date are examined, it is already clear that useful new information for crop and vegetation identification is present in comparison with the MSS. Especially band 5 gives additional information for discrimination of crops. The red band is very well located in the chlorophyll dip. Thermal information is useful, but especially the ground sample size will remain a limitation for use. In general one may state that with the introduction of the Landsat Thematic Mapper a useful remote sensing aid is introduced, because of his spatial and spectral resolution. It is possible with these data and some fieldwork to identify a large range of crops in the Netherlands per field. The mapping can be done in an easier way than with aerial observations. This can be used for different objectives. For instance, updating of landuse per field and to a certain extent prediction of production can be deducted from Landsat TM data. This makes the information of Thematic Mapper useful for a range of institutes and decision makers at provincial and state level.

Future research may for instance be directed to a determination of the different type of a single crop like varieties of potatoes. Thematic Mapper information is also useful as and aid for mapping soils and natural vegetation. The soil patterns may be deducted from the distribution and development of the crops or vegetation. Moreover, the incorporation of the Thematic Mapper data in geoinformation systems seems to be a good approach. In general multitemporal data will provide information on spectral characteristics in the different stages of crop and vegetation development and provide the possibility of monitoring growth stages of crops and variations in development. 


\section{G. F. EPEMA}

\section{Acknowledgements}

The author is greatly indebted to the Remote Sensing department of the National Aerospace Laboratory (NLR) for providing tapes and discussions on the information content of the Thematic Mapper. Also thanks is due to Professor S. B. Kroonenberg for making valuable comments to this paper.

\section{References}

Anuta, P. E., L. A. Bartolucci. E. Dean, D. F. Lozano, E. Malaret, C. D. McGillem. J. A. Valdes \& C. R. Valenzuela. 1984. Landsat-4 MSS and Thematic Mapper data quality and information content analysis. IEEE Transactions on Geoscience and Remote Sensing, Vol Ge-22 No 3: 222-236.

Bunnik. N. J. J., 1978. The multispectral reflectance of shortwave radiation by agricultural crops in relation with their morphological and optical properties. Doctoral thesis. Mededelingen Landbouwhogeschool Wageningen $78-1.175 \mathrm{pp}$.

Crist. E. P. \& R. C. Cicone. 1984. A physically-based transformation of Thematic Mapper data - The TM Tasseled Cap. IEEE Transactions on Geoscience and Remote Sensing. Vol. GE-22 No 3: $256-263$.

Kauth, R. J. \& G. S. Thomas, 1976. The tasseled cap-A graphic description of the spectral-temporal development of agricultural crops as seen by Landsat. Proceedings Symposium on Machine Processing of Remotely Sensed Data (Purdue University, West Lafayette, Indiana), pp. 4B-41 to 4B-50.

Menenti. M.. 1984. Physical aspects and determination of evaporation in deserts applying remote sensing techniques. Doctoral thesis. Wageningen Agricultural University. Netherlands, 202 pp.

US Geological Survey. 1982. Landsat Data Users Notes. Issue No 23. p. 1-12. Eros Data Center. Sioux Falls. South Dakota. USA.

Verhoef. W. \& N. J. J. Bunnik. 1974. Spectral reflectance measurements on agricultural field crops during the growing season. NIWARS Publication $31.72 \mathrm{pp}$. 